ARTICLE HISTORY: Received: January 4, 2021 Accepted: February 25, 2021 Published: March 3, 2021

\title{
VERIFICATION OF THE THEORY OF GENERATIONS IN PRACTICE ON THE EXAMPLE OF DISTANCE LEARNING
}

\author{
Kovin E.A. ${ }^{1}$ \\ ${ }^{1}$ Kovin Egor Andreevich - postgraduate student, 3 courses, \\ Department of Cultural Studies, Musicology and Music Education, \\ Faculty of Music, Sociological Sciences, \\ Perm State Humanitarian Pedagogical University
}

Russia, Perm

\section{ВЕРИФИКАЦИЯ ТЕОРИИ ПОКОЛЕНИЙ НА ПРАКТИКЕ НА ПРИМЕРЕ ДИСТАНЦИОННОГО ОБУЧЕНИЯ}

\author{
Ковин Е.A. \\ ${ }^{1}$ Ковин Егор Андреевич - аспирант, 3 курса, \\ кафедры культурологии, музыковедения и музыкального образования, \\ факультета музыки, направления сочиологические науки, \\ Пермский государственный гуманитарно-педагогический университет \\ Россия, г. Пермь
}

\begin{abstract}
In this article, the "XYZ generation theory" was tested, which has become popular in Russia nowadays. The founders of this theory are the American writers William Strauss and Neil Hove, who first presented their ideas to the general public in 1991 in the joint book "Generations". Since then, the "XYZ generation theory" has not exposed any significant changes, but despite this it remains dominant in both scientific and business circles. On the example of such a distinctive feature of generations as technical competence, the author of this article proved that the dominant theory of generations does not actually pass the test in practice in Russian realities.

Аннотация. В данной статье была проведена проверка «теории поколений XYZ», которая на сегодняшний день стала популярной в России. Основоположниками этой теории являются американские писатели Вильям Штраус и Нил Хоув, впервые представившие свои идеи широкой публике в 1991 году в совместной книге «Поколения». С тех пор «теория поколений XYZ» не претерпела никаких значительных изменений, но несмотря на это остается господствующей как в научных, так и в бизнес кругах. На примере такого отличительного признака поколений, как техническая компетентность, автором данной статьи было доказано, что господствующая теория поколений, на самом деле не проходит проверку на практике в российских реалиях.

Key words: verification of the theory of generations, generations Z, Y, X, technical competence of different generations, distance learning

Ключевые слова: верификация теории поколений, поколения Z,Y,X, техническая компетентность различных поколений, дистанционное обучение
\end{abstract}

На сегодняшний день, в России как в социологических науках, так и в бизнес кругах широко распространена «теория поколений XYZ», авторами которой являются американские писатели Вильям Штраус [6] и Нил Хоув [5], впервые представившие свою теорию широкой публике в 1991 году в совместной книге «Поколения» [4]. Не претерпев никаких серьёзных изменений, «теория поколений XYZ» продолжает быть актуальной. Это доказывает тот факт, что абсолютное большинство работ, касающихся, тем или иным образом, темы поколений, ссылаются на вышеприведенных авторов. В России была создана российская школа теории поколений «RuGenerations», которая не стала исключением, взявши за основу материалы В. Штрауса и Н.Хоува.

Согласно господствующим в России теориям, чем моложе человек, тем лучше он разбирается в современных технологиях, например, он лучше пользуется компьютером и другими различными гаджетами. Так, люди, родившиеся после 2003 года, «Поколение Z» или, как его называют российские авторы «цифровое поколение», уже с детства профессионально владеют современной техникой, а Интернет для них стал естественной средой обитания [2]. Не сильно отстали от «цифрового» поколения и «миллениалы» или «Поколение Ү», люди, родившиеся с 1984 по 2003 года, так как для них в подростковом возрасте дефицитом был хороший Интернет и игровые приставки, и они буквально «набросилось» на виртуальную реальность, когда она стала широко доступна, тем самым, не дав прогрессу уйти далеко без их внимания [1].

А вот «Поколению Х», люди, родившиеся с 1964 по 1984 года, уже сложнее осваивать современную технику, несмотря на то что подавляющее большинство «иксов» имеют аккаунты в социальных сетях, они ещё не отказались от прослушивания радио (не только в машине) и чтения бумажных газет. Что касается «Бейби- 
Бумеров», людей с датой рождения с 1944 по 1963 года, в России бытует мнение, что «бумеры» почти не пользуются различными мессенджерами и современными гаджетами, зато остаются неизменными лидерами по потреблению информации из газет и телевиденья [3].

В октябре 2020 года среди преподавателей Пермского государственного гуманитарно-педагогического университета был проведен опрос, касающийся адаптации сотрудников к дистанционному обучению, на которое был переведен ВУЗ, в связи с неспокойной эпидемиологической ситуацией в стране. В сумме было опрошено 147 преподавателей из четырех возрастных категорий: до 35 лет, от 35 до 50 лет, от 50 до 65 лет и старше 65 лет. Некоторые вопросы, тем или иным образом, были связаны непосредственно с технической компетентностью респондентов, давайте рассмотрим их более подробно.

В ходе опроса (табл. 1) выяснилось, что 75\% преподавателей старше 65 лет, ничего не докупали из технических устройств, чтобы вести дистанционные занятия.

В то же время, такой же ответ дали только $63,6 \%$ преподавателей, чей возраст составляет до 35 лет и лишь $52,6 \%$ преподавателей от 35 до 50 лет. Оказывается, более старшее поколение было лучше готово к дистанционному обучению в плане наличия технических устройств.

Табл. 1

Результаты ответов на вопрос «Вы докупали или не докупали, что-то из технических устройств, чтобы вести дистанционные занятия?»

\begin{tabular}{|c|c|c|c|c|}
\hline Вы докупали или не докупали что-то из технических устройств, чтобы вести \\
дистанционные занятия? & $\begin{array}{c}\text { До 35 } \\
\text { лет }\end{array}$ & $\begin{array}{c}35-50 \\
\text { лет }\end{array}$ & $\begin{array}{c}51-65 \\
\text { лет }\end{array}$ & $\begin{array}{c}\text { Старше } 65 \\
\text { лет }\end{array}$ \\
\hline 1. Нет, все необходимое у меня было. & 63,6 & 52,6 & 56,9 & 75,0 \\
\hline 2. Нет, все, чего мне не хватало, мне выдал Университет. & & 5,3 & 11,8 & 5,0 \\
\hline 3. Да, что-то пришлось докупать по мелочи & 27,3 & 29,8 & 23,5 & 5,0 \\
\hline 4. Да, мне пришлось существенно потратится на новую технику & 9,1 & 8,8 & 7,8 & 15,0 \\
\hline 5. Затрудняюсь ответить & & 3,5 & & \\
\hline
\end{tabular}

Разрыв между поколениями также наблюдается и с техническими возможностями общаться по видеосвязи, вновь не в пользу молодых преподавателей. (табл. 2).

Табл. 2

Результаты ответов на вопрос «Как Вы считаете, достаточно ли технических устройств, которыми Вы пользуетесь сегодня, для проведения занятий в формате видеосвязи/вебинара?»

Как Вы считаете, достаточно ли технических устройств, которыми Вы пользуетесь сегодня, для проведения занятий в формате видеосвязи/вебинара

\begin{tabular}{|c|c|c|c|c|}
\hline & лет & лет & лет & лет \\
\hline 1. Да. & 68,2 & 73,7 & 70,0 & 90,0 \\
\hline 2. Нет. & 22,7 & 15,8 & 20,0 & 10,0 \\
\hline 3. Другое & - & 7,0 & 4,0 & - \\
\hline 4. Затрудняюсь ответить. & 9,1 & 3,5 & 6,0 & - \\
\hline
\end{tabular}

Так, 90\% из опрошенных респондентов старше 65 лет, имеют все необходимые средства, чтобы общаться по видеосвязи, в то время как, только $68,2 \%$ преподавателей до 35 лет, ответили также.

Аналогичным образом обстоит ситуация и с оплатой за Интернет. На вопрос «Пришлось ли Вам или не пришлось увеличить оплату за Интернет после перехода на дистанционное обучение?», отрицательно ответили $90 \%$ от числа респондентов старше 65 лет, $72,5 \%$ от 51 до 65 лет, 50,9\% от 35 до 50 лет и $68,2 \%$ до 35 лет. Исходя из этих показателей, можно сделать вывод, что самым мощным Интернетом обладают старшие поколения, не смотря на кажущийся стереотип, что молодежи больше нужен такой Интернет для работы в профессиональных программах и компьютерных игр.

Табл. 3

Результаты ответов на вопрос «Испытывали или не испытывали Вы трудности при проведении занятий в дистанционном формате в целом?»

\begin{tabular}{|c|c|c|c|c|}
\hline \multirow{2}{*}{$\begin{array}{c}\text { Испытывали или не испытывали Вы трудности при проведении занятий в } \\
\text { дистанционном формате в целом?» }\end{array}$} & $\begin{array}{c}\text { До 35 } \\
\text { лет }\end{array}$ & $\begin{array}{c}35-50 \\
\text { лет }\end{array}$ & $\begin{array}{c}51-65 \\
\text { лет }\end{array}$ & $\begin{array}{c}\text { Старше 65 } \\
\text { лет }\end{array}$ \\
\hline 1. Точно да & 4,5 & 10,5 & 11,8 & 15,0 \\
\hline 2. Скорее да, чем нет & 27,3 & 19,3 & 21,6 & 15,0 \\
\hline 3. Скорее не возникало, чем возникало & 50,0 & 47,4 & 54,9 & 35,0 \\
\hline 4. Точно не возникало & 18,2 & 21,1 & 11,8 & 35,0 \\
\hline
\end{tabular}


Такой общий вопрос как «Испытывали или не испытывали Вы трудности при проведении занятий в дистанционном формате в целом», тоже не дал однозначных результатов (табл. 3). В той или иной мере трудности испытывали 31,8\% преподавателей в возрасте до 35 лет, 29,8\% от 35 до 50 лет, 33,4\% от 51 до 65 лет и $30 \%$ от 65 лет и старше. Как видно из показателей, возраст преподавателей никаким образом не повлиял на наличие или отсутствие каких-либо трудностей при проведении занятий на «дистанте».

Более того, на сбои с программным обеспечением жаловались лишь 9,1\% сотрудников университета старше 65 лет, в то время как аналогичную проблему отмечали 17,9\% респондентов от 51 до 65 лет, 27,3\% преподавателей от 35 до 50 лет и 17,6\% молодых сотрудников до 35 лет. Казалась бы, кто как не молодой состав преподавателей, не должен сталкиваться со сбоями в программном обеспечении, но на практике, оказалось, что более старшее поколение лучше разбирается в программном обеспечении, которое касается дистанционного обучения.

Исходя из вышеприведенных показателей, можно сделать вывод, что старшее поколение, а именно люди старше 65 лет, которые относятся к «Бэйби-бумерам», ничуть не хуже технически компетентны, а по некоторым показателям превосходят как «поколение X», так «поколение Ү». В частности, «бумерам» среди всех остальных поколений, пришлось всех меньше докупать необходимое оборудование для «дистанта», они были лучше всех подготовлены к видео общению, у них был самый мощный Интернет и меньше всех сбоев с программным обеспечением. Таким образом, можно смело утверждать, что сегодняшняя концепция теорий поколений, господствующая в российских реалиях не верифицирована на практике, и не имеет практического обоснования.

\section{Список использованной литературы}

1. «Поколения Y и Z: найди пять отличий» - [Электронный pecypc] https:/www.if24.ru/pokoleniya-y-i-znajdi-pyat-otlichij/ (дата обращения 12.12.2020 г.)

2. Российская школа Теории поколений - RuGenerations [Электронный pecypc] https://rugenerations.su/ (дата обращения 10.12.2020 г.)

3. «Теория поколений $\mathrm{X}, \mathrm{Y}, \mathrm{Z}$, беби-бумеров, альфа в России - их ключевые особенности и различия» [Электронный ресурс] https://prostudio.ru/journal/generation-x-y-z/\#article-comments (дата обращения 10.12.2020 г.)

4. Howe, Neil; Strauss, William (1991). Generations: The History of America's Future 1584-2069.

5. Wikipedia (2010), "Neil Howe", available at: https://en.wikipedia.org/wiki/Neil_Howe, (Accessed 18.02.2019)

6. Wikipedia (2010), "William Strauss" available at: https://en.wikipedia.org/wiki/William_Strauss (Accessed 18.02.2019)

\section{References}

1. "Generations Y and Z: find five differences" - [Electronic resource] https://www.if24.ru/pokoleniya-y-i-Z-najdipyat-otlichij/ (date of circulation 12.12.2020)

2. Russian School of Theory of Generations - RuGenerations [Electronic resource] https://rugenerations.su/ (date of circulation 10.12.2020)

3. "The theory of generations X, Y, Z, baby boomers, alpha in Russia - their key features and differences" [Electronic resource] https://prostudio.ru/journal/generation-xyz/\#article-comments (date of reference 10.12.2020)

4. Howe, Neil; Strauss, William (1991). Generations: The History of America's Future 1584-2069.

5. Wikipedia (2010), "Neil Howe", available at: https://en.wikipedia.org/wiki/Neil_Howe, (Accessed 02/18/2019)

6. Wikipedia (2010), "William Strauss" available at: https://en.wikipedia.org/wiki/William_Strauss (Accessed $02 / 18 / 2019)$ 